\title{
ENGINEERING DESIGN, INVENTION AND ENTREPRENEURSHIP FOR BACCALAUREATE AND ASSOCIATE DEGREE ENGINEERING STUDENTS AT PENN STATE ALTOONA COLLEGE
}

\author{
Eric Granlund, Sohail Anwar \\ The Pennsylvania State University, Altoona College
}

\begin{abstract}
This paper describes some of the methods used in teaching engineering design and the inventing process to freshman baccalaureate engineering students in their introductory engineering design course ED\&G 100. In this course students were asked to invent a new product, material, or process that would be marketable. The students could also choose to develop a modification of an existing product, material or process. Students were asked to describe their idea in a business letter and forward it to industry for evaluation. In some instances a response from industry was actually received by the students concerning the feasibility of their ideas. We feel this contact with industry so early in their educational career was very exciting for the students and may aide in student retention in the major.
\end{abstract}

The paper also briefly describes an instructional module entitled Design for Manufacture that was also used in ED\&G 100. This module was used in teaching students fundamentals of engineering design and design for manufacture. The module was developed by The New York State Curriculum for Advanced Technology Education (NYSCATE). In this project based learning module the students were given a chance to work in project teams and design a desktop CD Holder and build a working prototype of their design. The module employed a series of 11 Knowledge and Skill Builder (KSBs) activities and gave students experience in the design process and evaluation along with manufacturing techniques and materials and how they impact product design.

The paper also describes a design project that was completed by freshman two-year engineering technology students in their introductory engineering graphics/CAD course. This project required the students to design and generate a set of working drawings for an accelerator pedal of the ASME Student Baja Vehicle. The ASME Baja Vehicle was built by the Altoona College Student Chapter of ASME and competes every year against over 100 other engineering schools in durability and performance testing. Through this design project students learn many of the factors involved in designing machine components. Lastly, the paper briefly describes the 18-credit entrepreneurship minor and the courses that make up this minor as offered through The Pennsylvania State University. Many baccalaureate-engineering students are pursuing this minor to complement their engineering degree. 


\section{Introduction}

Various methods have been tried by the authors in teaching engineering design and innovation to associate and baccalaureate engineering students. Our most successful techniques center around project based learning activities that interest the students and encourage them to take a more active role in their learning. By including the manufacturing side of the design process it is hoped that the students will gain a practical understanding of the engineering design process and all that is involuded in bringing a product to market. To better prepare our engineering graduates in an age of rapid globalization, entrepreneurship is introduced at an elementary level as it is felt to be a real and necessary part of an engineering education and will add value to our graduates. No longer can engineers be concerned only with the technical side of product development and manufacturing but must be familiar with the marketing, finance and business basics of company start up and operation. This new insight for engineers may ultimately lead to better product innovation.

\section{ED\&G 100 Course Structure}

Engineering Design and Graphics (ED\&G 100) is an introduction to engineering design course for all freshman baccalaureate-engineering students at the Altoona College of the Pennsylvania State University. In this three credit-hour course, engineering design and principles are taught through team-oriented design projects supported by communication skills: graphical, oral, and written. The course is made up of three components with each component meeting for a single two-hour period once a week. This gives a total class meeting time of six hours per week for fifteen weeks.

The first component of the course introduces students to computer application skills using CAD. It also develops student design competencies in the topical area of communication. Topics covered include Internet navigation, website design, word processing, MS Power Point presentations, and computer aided design and drafting using AutoCAD.

The second component of the course deals with manual graphic and drafting skills. Students are introduced to the fundamentals of orthographic projection. The topics covered include multi-view projection, dimensioning, lettering, oblique and isometric projection, sectional views, tolerances, scales, and selected topics in descriptive geometry.

The third component of ED\&G 100 focuses on team-based engineering design projects. Working together in teams, students work on design projects selected from various disciplines of engineering. This component of the course introduces students to principles of engineering design practice while developing design competencies in 
problem definition, idea generation, evaluation and decision-making, implementation of teamwork, and process improvement.

It is the intent of the ED\&G 100 course to increase students' interest in the field of engineering with the hope of reducing the transfer rate of students who leave the engineering major. This course is one of only three engineering courses taken by students during their first two years at The Pennsylvania State University. The majority of the courses taken by students during the first two years of any baccalaureate engineering program at Penn State consist of mathematics, physics, chemistry, English, arts, social sciences, and humanities.

\section{ED\&G 100 Design Projects}

The first task given to students enrolled ED\&G 100 is to develop a new product, material, or process that could be marketable. The students may also choose to develop a modification of an existing product, material or process. Examples are given in class of past patented ideas and how some companies have increased their markets simply by just making variations of their current product line. Several articles related to engineering design and manufacturing processes are handed out in class. These articles give students information regarding the steps involved in the design process and the factors that must be considered when designing and manufacturing a product. The students are asked to present their ideas in the form of a one page proposal using MS Word. The proposal is graded for market feasibility and grammar. Once approved by the instructor, the students are required to perform an Internet search for a company that may be interested in their product idea and write a formal business letter introducing their idea to that company. It is the intent of the letter to receive feedback on the student design idea from a company representative such as an engineer.

Approximately twenty percent of the students receive some form of correspondence from industry. These companies include Sony Electronics, General Motors Corporation, Gateway, Lego Systems, Inc., Kraft Foods, K2 Skis, Master Lock Company, Easton Sports, Bestop Inc., Woods Industries and Extremely Large Plumbing Co. The feedback from industry may be a company waiver form requesting a signature from the student allowing the company to consider their product idea. Many times companies reply with a standard form letter stating they are not allowed to consider outside ideas for their products. On a few occasions students have received personal letters from a product development engineers outlining their thoughts on the students' design ideas. All student ideas and company correspondence are shared with the class. In some instances it is found that a student's product idea already exists. In these cases students are told to be encouraged and not discouraged because their product idea was good enough to actually make it to the market.

Some examples of student product ideas include Liquid PEZ dispensers, electronic carpenters level, LEGO hospital theme, electronic shower temperature control, focusable automobile headlights, remote entry system for household doors, disposable travel toothbrush containing toothpaste in the handle, portable campfire ring to contain 
campfires, automatic tint automobile windows, shock absorbers for wave runners, disposable cellular phone, Swedish-Fish flavor ice cream, microwave inside a standard oven, 9-1-1 button on remote car door opener, varying intensity automobile brake lights.

It is the authors feeling that contact with industry so early in their educational career is very exciting for the students and should aide in student retention within in the engineering major.

\section{NYSCATE Design for Manufacture Project ED\&G 100}

The New York State Curriculum for Advanced Technology Education (NYSCATE), a consortium of two-year and four-year institutions (Finger Lakes Community College, Fulton Montgomery Community College, New York City Technical College, and Hofstra University), is currently developing, field testing, and preparing for distribution of fourteen grade 9-14 advanced technological education curriculum modules. The modules represent three areas of technology bio/chemical, information, and physical sciences. Each module features the integration of mathematics and science principles through informed design.1

In the NYSCATE module Design for Manufacture students work in groups to:

- understand and investigate possible solutions to a given problem;

- investigate the problem by completing Knowledge and Skill Builder (KSB) activities, and by using information resources that they identify;

- prepare a report showing how they considered important factors in making their design decisions;

- base their design and redesign upon technological, scientific, and mathematical concepts;

- $\quad$ see that their design meets specifications and constraints;

- use appropriate tools and materials to build a model of their design, which is useful in illustrating, analyzing, and defending their design decisions;

- develop and use a repeatable and reliable method for testing their design; and

- make or propose improvements to their design on the basis of their analysis and testing.

In the NYSCATE module Design for Manufacture features a design challenge, which consists of designing a desktop CD holder, taking into account factors to optimize its manufacture. The CD holder must have the capacity to hold at least 20 standard-sized CDs on a desktop. Students do not need to overly concern themselves with features of the CD holder. It is to be assumed that there is a large demand for containers and any reasonable features chosen by students will sell in the marketplace. The holder can be a drawer style, stackable, open style, flip style, etc. The following steps are involved in this design challenge:

(1) Student teams are established and charged with designing a desktop CD holder according to the above-mentioned specifications. Each team consists of 3-4 students. 
(2) The challenge faced by students involves designing a CD holder that optimizes its potential for manufacturing. Many students would like to proceed with the design challenge by trial and error. To prevent this, they must be convinced that they need to find out what they now know as a group and what they will need to know about the process of design, and about design for manufacturing, in order to complete the challenge properly. The Knowledge and Skill Builders (KSBs) activities are meant to help students become more informed about the process of design and about design for manufacturing. All of the following KSBs are supposed to be covered during the module. However, the length of treatment given to each topic is at the discretion of the faculty. The KSBs included the following topics:

KSB T-1: The Informed Design Cycle

KSB T-2: Product Design Considerations

KSB T-3: Manufacturing Methods-Materials

KSB T-4: Manufacturing Methods-Construction Elements

KSB T-5: Manufacturing Methods-Assembly Techniques

KSB T-6: Manufacturing Methods-Coating

KSB T-7: Manufacturing Methods-Packaging

KSB T-8: Manufacturing Methods-Automation

KSB T-9: Reverse Engineer a Product

KSB T-10: Find a Good Example of Designing for Manufacture

KSB T-11: Estimate/Calculate Materials Required

(3) Every student team is required to maintain either a design folio or a design journal in which team members gather and record information as they complete the design challenge.

(4) Every student team is required to prepare a final design report in which team members' work and findings are summarized. The final design report is a written report in which at least two product styles are compared. For example, a team might look at a drawer-type CD holder versus a flip-lid type. The report should include an evaluation of possibilities presented by various manufacturing methodologies studied in this course. In addition, the design decisions made by the student team must be justified in the report.

(5) The student team is required to build a model of one of the styles analyzed in the written report. The model does not have to be made of the same material or use the same methodologies recommended in the written report, but it should illustrate some of the major design decisions made by the student team. This model can be a physical model or a 3-D virtual model constructed using CAD.

(6) Every team is required to develop a group presentation to explain how the team members met the design challenge.

(7) All the student teams are assessed on the quality of their work on Knowledge and Skill Builders (KSBs), design journal or design folio, final design report, model, and group presentation. 
Penn State Altoona College has a student chapter of ASME. The chapter in has been involued in the yearly ASME Student Baja Vehicle Competition. In this competition the students are required to build a vehicle powered by an 8 horsepower Briggs and Stratton engine. The students must design and build most of the vehicle from scratch, including the frame. The vehicle must meet certain safety requirement along with performance requirements. The cars are all tested at a yearly competition with over one hundred other engineering schools in early June.

The Pennsylvania State University Altoona College offers two ABET accrediated associate engineering technology degrees in Mechanical and Electrical Engineering Technology. The degrees are approximately 72 credits each. After successful completion of a two year associate degree students may elect to continue their education an additional two years and enroll in a baccalaureate of science in engineering technology degree program such as the Baccalaureate of Science in Electro-Mechanical Engineering Technology program as offered at the Altoona College. Other ABET accredited four year engineering technology degrees that are offered within the Penn State system include Electrical, Mechanical, Civil and Construction Management and Plastics Engineering Technology.

As a method to get more associate engineering technology students involved in the design and fabrication of the Baja vehicle, freshman two-year engineering technology students in their introductory engineering graphics/CAD course, Engineering Graphics Technology 101, are required the students to design and generate a set of working drawings for the accelerator pedal of the ASME Student Baja Vehicle. Through this design project students learn not only how to generate a set of working drawings using AutoCAD software but also the steps necessary in designing a product within certain design constraints. The resulting working and assembly drawings are then given to the ASME Student Baja Design Team for consideration and possible use in the vehicle. The students have found this project very interesting as it is more hands-on than a design project selected from a graphics text. Moreover, it is very I open ended giving the students a chance to generate many solutions to a given design problem.

\section{Entrepreneurship Minor}

The Engineering Entrepreneurship Minor (E-SHIP) is an interdisciplinary, crossuniversity minor open to all students but designed for engineering, business and IST (Information Sciences and Technology) students who aspire to be innovation leaders for new technology-based products and companies. 2 The courses in the minor use a problem-based teaching methodology. The classes are setup in such a way such that engineering and IST students will learn basic business principles and business students will learn the basic engineering design process. 
The 18-credit E-SHIP minor is made up of four core courses (12 credits) that for engineering students include:

ENGR 310: Entrepreneurial Leadership. Coverage of the fundamentals of leadership, including theory, understanding of individual leadership styles, group and organizational leadership, values and ethics, and life cycles of organizations. This knowledge base supports an entrepreneurial project in the second part of the semester, when student teams select a "need-based" product, and do prototyping, strategic planning, business feasibility analysis, basic costing, business plan generation, customer feedback. 2

ENGR 411: Entrepreneurial Business Basics. Provides coverage of the three knowledge areas most lacking in engineering students with new venture creation interests: Finance, Intellectual Property (PI), and Marketing. Problem-based learning is a key component of the course, with group-based investigations of current business/technology topics which pull in business finances, PI, and marketing. Such as the Firestone/Bridgestone and Napster cases. The primary objective of this course is to get you to think as a blend of an engineer and a business person, using all relevant facts in technology business reviews. 2

ENGR 407: Technology-Based Entrepreneurship. Individual and team-based tasks that draw out creative thinking skills, and forces students to become risk-takers, and to experience failure. The guiding principal for the course is that entrepreneurs are innovators and operate in an uncertain, risky environment where failure is endemic. The issue is not how to avoid failure, but how to learn quickly from the failures and capitalize on the knowledge gained - a process known as Intelligent Fast Failure. 2

ENGR 430: Entrepreneurship and New Product Development. Explores the entrepreneurial mindset within a conventional company, and the process of new product line launch. Student teams will design, prototype a new product family, and then present the product concept to venture seed fund representatives from companies like General Electric. Teamwork, cost and pricing, prototype quality, and market need assessment are all factors in a successful product family proposal. 2

These core engineering entrepreneurship courses give engineering students much needed information on all facets of new product ventures and marketing and a fresh perspective on engineering design and innovation. These skills will give extra value to our graduates and may be the needed advantage they will need to compete in an increasingly competitive global marketplace. 


\section{Conclusion}

The paper described some of the methods used to teach engineering design and invention process to all freshman baccalaureate engineering students at the Altoona College of the Pennsylvania State University. The primary vehicle used to teach engineering design and invention process to freshman engineering students is a three credit-hour course titled Engineering Design and Graphics 100 (ED \&G 100). The paper also described an instructional module titled Design for Manufacture that was used in ED\&G 100 course. This module was used to teach fundamentals of engineering design to freshman engineering students. The paper also presented a description of a design project that was conducted by two-year engineering technology students in their introductory engineering graphics/CAD course. Lastly, the paper described the 18 credit-hour entrepreneurship minor. The Engineering Entrepreneurship Minor (E-SHIP) is an interdisciplinary minor open to all students. However, the entrepreneurship classes are designed in such a way that engineering students will learn basic business principles and business students will learn the basic engineering design process. Many engineering students are pursuing this minor to complement their baccalaureate engineering degrees.

Bibliography

1. Anwar, S., and Granlund, E. "Enhancing a Freshman Level Engineering Design Course Through Project Based Learning. " Proceedings of the 2003 ASEE Annual Conference. Session 2653. Available CD-ROM.

2. Web: http://e-ship.ecsel.psu.edu

Biography

Eric Granlund

Eric Granlund holds a M.E. degree in Engineering Mechanics from The Pennsylvania State University and a B.S. degree in Mechanical Engineering from The Pennsylvania State University. He currently teaches in both the baccalaureate engineering and engineering technology programs at The Pennsylvania State University, Altoona College. $\mathrm{He}$ is faculty advisor of the engineering honor society Tau Alpha Pi student chapter at Altoona College. He has developed and taught numerous children's engineering courses and is a member of ASEE and ASME.

Sohail Anwar

Sohail Anwar holds a Ph.D. degree in Industrial and Vocational Education from the Pennsylvania State University and a M.S. degree in Electrical Engineering from the University of Texas at Arlington. He completed additional graduate coursework in control theory and applied mathematical sciences at the University of Texas at Arlington. $\mathrm{He}$ is currently serving as an associate professor of Engineering and the program coordinator of Electrical Engineering Technology at The Pennsylvania State University, Altoona College. Since 1996, he has also served as an invited professor of Electrical Engineering at IUT Bethune, France. 